\title{
Yapay Zekânın Luditleri Kimler Olacak?
}

\author{
DOI: 10.26466/opus. 944914
}

\author{
Abdurrazak Gültekin* \\ * Öğr. Gör. Dr., Bingöl Üniversitesi, Fen-Edebiyat Fakültesi, Bingö1/Türkiye \\ E-Posta: abdurrezakgultekin@gmail.com \\ ORCID: $0000-0003-4832-3258$
}

\section{Öz}

Tarihte makine kırıcısı olarak bilinen Luditler ile yapay zekâ karşıtları arasında ilişki kuracağımız makalemizde yapay zekânın tanımı, kısa tarihçesi ve insanlar açısından önemine değinilecektir. Bu bağlamdan hareketle yapay zekâya karşı çıkan görüşlerin neden karşı çıktıklarını ve bu yapay zekânın, hangi aşamada insanlara zarar verecek durumda olacağı hakkında betimleyici bir anlatım sunulacaktır. Zayıf yapay zekâ, güçlü yapay zekâ olarak insanın zihinsel süreçlerini yerine getirdiğinde onun etkinlik gücünün artacă̆g belirtilecektir. Bunun yanında yapay zekâya karşı çıkan insanların, tarihteki makine kırıcıları ile benzer bir düşünceye sahip olup olmadıkları konusu tartışılacaktır. Yine bu çalışmada Ludist akımların teknoloji karşıtlığı, makine kırıcılı̆̆ fikri, bu fikri olumsuz yönden değerlendiren düşünceler karşılaştırılacaktır. Yapay zekâ karşıtlarının düşünceleri ile geleneksel ludistlerin ve neo ludistlerin benzer ve ayrışan yönleri tartışılacaktır. Çă̆daş ludist olarak tanımladığımız 21. yüzyıl teknoloji karşıtlarının, özelde yapay zekâ karşıtlarının kaygıları, insan nesli ve insanlık üzerinedir. Onlara göre yapay zekâ, bu alanları tahrip edip, yok edecektir. Çalışmamızda bu konu detaylıca açıklanacaktır.

Anahtar Kelimeler: Yapay Zekâ, Luddit, Luddist, Makine Kırıcısı, Teknoloji. 


\title{
Who Will be the Ludits of Artificial Intelligence?
}

\begin{abstract}
In our article, in which we will establish a relationship between the Ludites, known as machine-breakers in history, and the opponents of artificial intelligence, the definition of artificial intelligence, its short history and its importance for humans will be mentioned. In this context, a descriptive narrative will be presented about why the opinions that oppose artificial intelligence are opposed and at what stage artificial intelligence may be in a position to harm people. It will be stated that when artificial intelligence fulfills human mental processes as a strong artificial intelligence, its efficiency will increase. In addition, it will be discussed whether people who oppose artificial intelligence will have a similar idea with machine breakers in history. However, the opinions of those who evaluate the anti-technology and machinebreaking idea of Ludist movements negatively and those who view artificial intelligence negatively will be compared. The thoughts of opponents of artificial intelligence and the similarities and differences between traditional ludists and neo-ludists will be discussed. It will be explained that the concerns of the opponents of 21st century technology, which we define as contemporary ludists, and in particular the opponents of artificial intelligence, are about the human race and humanity and that artificial intelligence will destroy and destroy these areas.
\end{abstract}

Keywords: $\quad$ Artificial Intelligence, Luddite, Luddist, Machine Breaker, Technology. 


\section{Giriş}

İnsan hayatında teknoloji büyük bir önem kazanmıştır. Günümüzde teknolojinin girmediği bir alan bulmak çok zor görünmektedir. Teknolojinin insan hayatına bu kadar dahil olduğu bir ortamda ondan bağımsız yaşamaya çalışmak ve etkisinden ayrı bir dünya kurmak oldukça zordur. Çünkü yirminci yüzyılda dünyadaki bilimsel ve teknolojik gelişme yaşamın birçok alanını derinden etkilemiştir (Alkayış, 2020, s.225). Teknolojinin insan hayatına etkisi olumlu olarak değerlendirileceği gibi olumsuz da değerlendirme yapılacak bir alandır. Bu noktan hareketle teknolojiye bakış açımız, aslında ondan pratik anlamda yararlanma düzeyimize göre değişmektedir. Teknoloji insan hayatını kolaylaştıran ve hayat konforunu artıran bir araç olarak görüldüğünde gayet olumlu bir alan olarak anlaş1labilir. İnsan hayatını ve sosyal becerilerini kısıtlayan, hayat düzenini ve ekonomik yapısını bozan bir bakış açısına göre değerlendirildiğinde teknolojinin olumsuz bir alan olduğu düşünülmektedir.

Yapay zekâ destekli bilgisayarlar gündelik hayatımıza girmiş bulunmaktadır. Hayatımızı bu kadar etkileyen yapay zekâ, ilerleyen zaman diliminde insan eylemlerinin hemen hemen hepsini yaptığında bir insan olarak yapay zekâya bakış açımız nasıl şekillenecektir? Ona kendi konforumuzu arttırıcı bir alan olarak mı bakacağız? yoksa insanlığı yok edecek bir düşman olarak mı bakacağız? Bu anlamda yapay zekânın durumu ne olacaktır? gibi çeşitli sorular gündeme gelmektedir. Çünkü yapay zekâ, insan türünü ortadan kaldırabilecek kadar yetkin ve donanımlı olacağına dair düşüncelerin olduğu göz ardı edilmemelidir. Bu durumda tarihte işçilerin işini elinden alan makinelere karşı gelişen bir akım olan makine kırıcıları gibi insanlığı yok edebilecek yapay zekâya karşı böyle bir akım gelişecek midir?

\section{Teknoloji ve Ludist Tepkiler (Üretici Kızgınlığından Tüketici Hoşnut- suzluğuna)}

Genel anlamda insanların kendi çevrelerini kontrol etmek için kullandıkları araçlarla ve teknik bilgi ile meydana gelmiş olan maddi kültürün tamamını ifade etmektedir. Íkincil olarak teknoloji, makinalar ve teknik donanım araçlarının birleştiği üretim tekniği olarak bilinir. Aynı zamanda 
endüstriyel faaliyetlerde kullanılmakta olan araç ve gereçlerin incelenmesi olarak da anlaşılır. Bu bakımdan değerlendirildiğinde teknolojinin bilimsel devrimler sonucunda meydana gelen teknolojiye, modern teknoloji adı verilirken üretim maliyetlerinin azaltılması, üretim aşamalarının verimliliğinin arttırılması için kullanılan teknolojiye, yeni teknoloji adı verilir. Buharlı makinelerin üretilmesi, içten yanmalı motorların üretilmesi gibi buluşlar yeni teknoloji olarak ifade edilmektedir (Cevizci, 2017, s.835).

Kelime anlamı yukarıda verilen teknoloji, etimolojik olarak incelendiğinde tekne kökünden türetilmiştir. Tekne ya da Tekhne iş, beceri ve uğraş anlamlarına gelmektedir. Bu kelimeden türetilen teknik ise işle ilgili, beceriyle ilgili olan tekhnos olarak bilinmektedir (Eyuboğlu, 2017, s.652).

Sümerlerden itibaren insanlığın ortak malı olarak kullanılan geleneksel saban, emek ve iş gücünün sembolü olarak kullanılmıştır. Ancak gelişen teknoloji ve sanayi devriminin etkisiyle işin ve üretimin sembolü artık buharlı makineler olarak anlaşılmaktadır (Gencer, 2012, s.10). Bu bağlamda düşünüldügünde sanayi devrimi sadece ekonomik anlamda değil toplumsal ve kültürel anlamda da büyük bir değişime yol açmıştır.

Teknolojinin gelişimi, toplumsal yapıyı da şekillendirmektedir. Teknolojinin toplumsal yapıyı etkilediği en önemli olaylardan birisi Ludist akımı olarak bilinmektedir. Bu akımın isim babası Ned Ludd'dur. Böyle birisinin yaşayıp yaşamadığı tam olarak bilinmemektedir. Çalışma hayatında meydana gelen değişiklik ve teknolojik ilerleme ile emeğin makineleşmesi sorunu meydana gelmiş ve bu durumda insan işçilerin yerini makineler almıştır. Anlatılan efsaneye göre Ludd, bir eve girerek içeride bulunan yeni keşfedilmiş bütün dokuma makinalarını kırmıştır. Çünkü bu aletler birçok tekstil iş̧̧isini işinden etmiştir. Bu olaydan sonra İngilizler arasında yeni keşfedilen teknolojik aletlerin başına ne zaman bir zarar gelse "Ned Ludd did it" "Ned yapmıştır" şeklinde bir deyim gelişmiştir (Arif, 2015). Teknolojinin geleneksel insan emeğine dayalı, insan gücünün yerini almasına karşı çıkan ludist akım, ludizm olarak anılmaktadır. Sanayileşmenin erken döneminde meydana gelmiş makinelerin artışını protesto eden eylemleri tarif etmek için geleneksel ludizm terimi kullanılmaktadır (Taymaz, 1998, s.1). Bu akım, ilkel ve geleneksel olarak teknolojiye karşı tepkilerini saldırı ve şiddet kullanarak göstermektedirler. Bu akımın 
başlattığı, insanın yerinin makinalara devredilmesi sonucunda ortaya çıkan, makinaların yayılmasına karşı insan emeğini savunan eylemler, oldukça şiddetli ve güç kullanılarak bastırılmıştır.

20. yüzyılın ikinci yarısının başında mekanik olarak yün biçme makinelerinin parçalanması ile başlayan ludist benzeri eylemler, ilk olarak Nottingham'da başlamıştır. Daha sonra tüm İngiltere'ye yayılmasıyla ortaya çıkan Luddizm akımının gelişmesine neden olmuştur. İngiltere'den farklı bölgelere yayılmasını önlemek için ölümle sonuçlanacak birçok ciddi yasa konulmasına rağmen bu tür makine kırıcı ve tahrip edici eylemlerin gelişmesi engellenememiştir (Beer, 1989, s.460). Nitekim yapılan eylemler sonucunda yakalanan eylemcilerden 17 tanesi 1813 yılında idam edilmiştir (Arif, 2015). Her ne kadar makineleşmenin insan istihdamına etkileri konusu olumlu ve olumsuz yönden değerlendirilse de Ludizm akımı insan zihninde teknolojinin kötü bir şey olduğu imajı oluşturmaktadir.

Luddizm, kökende, teknolojiyi adil ve sorumlu kullanmaktan çok makineyle ilgilidir. Bunun yanında geleneksel istihdam ve üretim standartlarını savunan bir hareket olarak değerlendirilmektedir. Ludizm, işçi sınıfının endüstriyel teknolojiye direnişini temsil eder. Çoğunlukla isyan ve kısa sokak eylemlerine dönüşen ludist gösteriler, aralıklı olarak gelişmiştir. Eylemlerin önüne geçmek için yukarıda söylendiği gibi ağır cezalar verilmekle birlikte herhangi bir makine kırıcısını açı̆̆a çıkaran ve mahkûm edilmesini sağlayan kişilere, 50 sterlinlik ödül verilmesine dair bildiri de yayımlanmıştır (Luddism , 2020).

Ludist isyan, unutulmuş olsa da teknolojiye karşı acımasızca saldırı gerçekleştiren kişileri temsil etmek amacıyla, ludist kavramı, politik ve sosyal alanda yerleşmiş bir sözcük olarak kullanılmaktadır. Bu akımın çeşitli alanlarda temsilcileri bulunmuştur. İngiliz şair Lord Byron Song for the Luddites adlı eserinde ludistleri övmüştür. $O$ şiirinde şu ifadeleri kullanmıştır: “Dövüşerek öleceğiz ya da özgür yaşayacağız; Kral Ludd sayesinde tüm kralları devireceğiz" (Arif, 2015).

Yukarıda belirtildiğinden hareketle buharlı makineler ve içten yanmalı motorlar gibi yeni teknolojik ürünlerin insan hayatına girmesi, yaklaşık olarak 250-300 sene öncesine dayanmaktadır. Yeni teknolojik ürünlerle birlikte, fabrikalar, insanların kol gücünden ziyade makinelere ihtiyaç duymaktadır. Teknolojinin gelişmesi, toplumsal ve ekonomik anlamda 
gelişim sağlamakta ancak bununla birlikte toplumsal düzen ve sosyal hayatı da değiştirmektedir. Teknolojinin kültürü etkileme söylemi yani teknoloji-kütür ilişkisi ile teknoloji-emek ilişkisi farklı algı tarzlarını meydana getirmiştir. Teknolojinin insan emeğine karşı bir tehdit olduğu söylemi, ludist akımın geleneksel tavrını temsil ederken teknolojinin kültürü değiştirmesi söylemi ve sosyal hayatı dönüştürmesi söylemi yeni tür ludist akımı temsil etmektedir. Bunun yanında teknolojinin yapay zekâ ile geliştirilmiş hali, sadece emek ve kültür bağlamında değil felsefi ve ontolojik düzlemde de dönüşüm ve değişim getirdiği ortadadır. Yapay zekâ destekli teknolojilerin insan nesliyle doğrudan etkileşimli bir alan olması da başka bir ludist akım ortaya çıkarmış gibi görünmektedir. Geleneksel ludistlerden ayrı olarak yeni ludist akım, genellikle geleneksel anlamda ludistlerden farklı olarak yıkıcı eylemler ve saldırgan davranışlar gerçekleştirmemektedirler. Gündelik hayatta teknolojik ürünlerin kullanım düzeyleri ve kullanım şekillerini eleştirel olarak ortaya koymaktadırlar (Çalış ve Erkan, 2013, s.179).

Doğal süreç içerisinde insan hayatını kolaylaştıracak ve maliyeti azaltacak üretim aşamasındaki yeni teknolojik ürünlerin, kullanılıp kullanılmaması, ürünün kar ve zarar endeksli değerlendirilmesine bağlıdır. Yeni ürün, kazanç artıracak düzeyde ise ve maliyeti azaltacak düzeyde ise kullanılır aksi durumda kullanılmamaktadır (Bülbül ve Özbay, 2007, s.20).

Klasik ludizmin çorap sanayinden başlayarak birçok işçi grupları arasında yayılmaktadır. Bunun gibi iş gücü alanında sorunlar yaşandığı zaman ve emeğin karşılığı alınmadığında, işverenler bu tür eylemlerin yapılabileceğinden korkmaktadır. Bundan dolayı ludizm, işçiler ve iş verenler arasında bir tür pazarlık aracı olarak kullanılmaya başlanmıştır. Pazarlık eğer işçiler lehine sonuçlanmazsa iş yelerinin ve makinelerin, işçiler tarafından tahrip edilme ihtimali bulunmaktadır. Bu yönüyle ludist hareket, açık bir şekilde olmasa da devrimci olarak nitelenebilir (Thomson, 1991, s.664).

İşçi sınıfının ludist eylemleri, iki farklı şekilde okunmaktadır. Bunlardan birincisi, işçilerin doğrudan makinelere düşmanlığı, ikincisi ise işverene zarar verme düşmanlığı anlamında değerlendirilmektedir. İşverene karşı kendi haklarını korumak için işçilerin iş verenin mülkiyetine, hammaddeye karşı bir zarar verme durumu olarak görülmektedir. İşverene 
karşı en hassas zararın nasıl olacağına dair bir tür eylem biçimi olarak görülür. Bunun yanında bir de işçilerin ikinci tür ludist eylemleri bulunmaktadır. Bu eylemler, makinelerin üretilmesi sonucunda kendi işlerini kaybetmiş olan işçilerin, iş verenin işçi tasarrufu yapmasına karşı çıkarak doğrudan sanayi devrimi sonucu üretilen makinelere karşı isyan ve yıkım eylemlerini temsil etmektedir (Çalış ve Erkan, 2013, s.162-163). Ludist eylemler özellikle erken dönem sanayii devrimi sonrasında daha çok şiddet eğilimli protestolar şeklinde olmuştur. El işçileri, kaybettikleri itibar, para ve alışık oldukları hayat standardından onları alıkoyan tek sebebin makinalar olduğunu düşünürler. İşçiler, makineleri ortadan kaldırdıkları zaman tekrar işlerine ve itibarlarına ulaşacaklarını düşünmektedirler. Bu tür eylemler aslında gelecek yüzyıllarda teknolojiyle insanların nasıl bir etkileşim ve savaş vereceğinin de habercisi olarak görülmüştür.

Sanayi devriminin erken döneminde başlayan ludist akım, gelişen teknoloji ve ilerleyen dönemlerde evrilmeye başlamıştır. Çünkü teknolojik ürünler, zaman içerisinde insanların emeğinin yerini almış böylece bir takım işsiz sınıfın oluşmasına neden olmuştur. Ancak yeni iş kolu meydana getirmiş, bu yönüyle iş̧̧i sınıfının işsiz kalmasından daha çok teknolojin kültürel yansımaları tehdit unsuru olarak görülür hale gelmiştir.

Sanayi devriminden sonra teknolojik gelişmelerin askeri ve ekonomik olmak üzere iki ana unsuru bulunmaktadır. Bir teknolojik ürün, bu iki unsur açısından faydalı ise kabul edilip üretilmektedir. Ancak son dönem çalışmalarda bu iki unsura başka diğer unsurlar da eklenmek zorunda kalınmıştır. Üretilen teknoloji, çevresel ve toplumsal anlamda faydalı olup olmadığına da bakılarak üretilmesi gerekmektedir (Toffler, 1996, s.211212). Bu bağlamda değerlendirildiğinde erken dönem ludist eylemlerin amacından farklı olarak yeni dönem ludist eylemlerin amacının çok farklı olduğu görülmektedir.

Yeni dönem ludist eylemler, teknolojiye körü körüne karşı olma, iş ve statülerini korumak amacıyla gelişmiş eylemler değildir. Bu eylemler, çevresel sorunların farkında olan ve toplumsal duyarlılığı olan insanlar tarafından meydana gelmiş, eylemsel tavırlar olarak değerlendirilmesi gerekmektedir. Bu düşünceye göre insanlık açısından daha yaşanabilir sosyal ve çevresel alan sunmak ve bunlara zarar veren her türlü teknolojik yeniliği reddetmek gerekir. Yeni dönem ludistlerde, erken dönem ludistlerin üretici kızgınlığından daha çok tüketici hoşnutsuzluğuna doğru bir 
evrilme gerçekleşmiştir (Çalış ve Erkan, 2013, s.167-168). Toffler'a göre (1996, s.214-215) yeni ludistler, teknolojinin dünyaya onarılması mümkün olmayan zararlar verdiğini iddia etmektedirler. Bu bağlamda yeni dönem ludistler, üretilen teknolojilerin oldukça fazla denetimlerden, özellikle çevresel zararlarını göz önüne alacak testlerden geçirilmesi gerektiğine inanmaktadirlar.

Yeni dönem ludist akımın en önemli temsilcisi Theodere Kaczynski olarak düşünülmektedir (Orhan ve Savuk, 2014, s.14). Kaczynski'e göre sanayi devrimi, insanlık için çok önemli sonuçlar meydana getirmiştir. Gelişmiş ülkelerde yaşayan insanların hayattan beklentileri, dünyanın dengesini bozmuş ve dünyada yaşam artık anlamsız hale getirmiştir. Bu haliyle sadece üçüncü dünya ülkelerinde psikolojik ve sosyal sorunlar yaratmışken, gelecek zaman diliminde gelişmiş ülkelerde de yaygın psikolojik ve sosyal sorunlar meydana getirecektir. Ona göre teknolojik ilerleme devam ederse çok daha fazla sorunlar insanları beklemektedir (Kaczynski, 1996, s.1-2). Herkeste ortak bir insan doğası bulunduğu bilinmektedir yani her insan evrensel bir kavramın tikel temsilcisidir (Çelebi, 2010, s.94). Buradan hareketle insanlar için ortak olan doğasına aykırı teknolojik gelişme bir felaket olabilir.

Yeni ludist olarak bilinen Kaczynski'nin teknolojiye bakış açısı birçok insanı etkilemiştir. Teknolojinin insanları yeni bir yok oluşa sevk ettiğine dair düşünceleri yapay zekâ konusunda gelecek dünyaya neredeyse bir uyarı niteliğindedir. Çünkü 21. yüzyıl teknoloji karşıtlı̆̆ ve özellikle yapay zekâ destekli teknolojik ürünler, insanlığın sonunu getireceği yönünde endişelere yol açmaktadır. Kaczynski'nin teknoloji karşıtlığı, sanayi devriminden sonra, teknoloji sevenlerin amaçlarının ne kadar gerçekleştiğine bakmakla anlaşılmaktadır. Ona göre teknoloji severler, insanların daha huzurlu ve insanların yaşamı için her şeyin daha konforlu olacağı bir dünya yaratmak için çalışmaktadırlar. Ancak teknolojinin iyi yönleriyle kötü yönlerini birbirinden ayırmak mümkün değildir. Bu bağlamda düşünüldüğünde kıtlığı önlemek için üretilen ilaçlı gıdalar, ölüm oranını azaltacak bu da insan ölümünü engelleyecek ve nüfusu arttıracak, kalabalık dünyada insanlar stresli bir hayat sürecektir. Bunun yanında fakirliğin ve hastalıkların son bulacağı bir dünyada da aynı sorunlar meydana gelecektir (Kaczynski, 1996, s.53-54). 


\section{Yapay Zekâ ve Karşı Tepkiler}

Teknoloji karşıtı neo ludist Kaczynski'nin karşı çıktığı konulardan bir tanesi de yapay zekâ konusudur. Ona göre yapay zekâ, mümkün olursa insanların hayatı makinalara bırakılmış olacak ki bu oldukça tehlikeli bir durumdur. Eğer yapay zekâ, mümkün olmayacaksa da yine işsiz bir sinıf kitlesi oluşacaktır (Kaczynski, 1996, s.54-55). Kaczynski'nin ifade etttiği güçlü yapay zekâdır. Zayıf yapay zekâ günümüzde bilgisayar destekli gelişmiş makinleri temsil etmektedir.

Yapay zekânın kendisinden korkulacak bir alan olup olmadı̆g 1 ve hangi seviyeye ulaştığına dair değerlendirme yapabilmek için öncelikle yapay zekânın tanımını ve kısaca tarihsel seyrini açıklamak yerinde olacaktır.

Antik Yunan'a kadar geri götürebileceğimiz insan benzeri varlıklar yapma çalışmaları, çağımızda insan eylemlerini taklit eden ve daha ötesi düşünebilen bir varlık meydana getirme üzerine yoğunlaşmış gibi görünmektedir. Günümüzde daha özel bir anlamda kullanılan yapay zekâ adı her ne kadar 20. yüzyılın ikinci yarısının başında, bir yaz okulu çalıştayında, konulmuş olsa da kaynaklarını ve hazırlayıcılarını çok daha eskilere götürmek mümkündür. Bu noktadan hareketle günümüz yapay zekânın, kavramsallaştırılması ve bu kavramın genel olarak ne anlamda kullanıldı̆̆ına bakmak faydalı olacaktır.

Yapay zekâ (Artificial Intelligence) bilgisayar denetimli makinelerin insana özgü davranışları, yerine getirme yeteneği olarak anlaşılmaktadır. Bu davranışlar; düşünme, hayal kurma, anlam verme ve yüksek zihinsel süreçler olarak anlaşılmaktadır (Nabiyev, 2016, s.25). Yapay zekâ, bilgisayar biliminin akıllı, dili kullanabilen, akıl yürütme yapabilen, gibi niteliklere sahip olan bilgisayar sistemleri tasarlamakla uğraşan bir kolu olarak görülmektedir (Güzeldere, 1998, s.27). Yapay zekâ kavramına, ilk olarak Dartmouth konferansında rastlanmıştır. 1956 yılında zekâ ile desteklenecek bilgisayarların olanaklılı̆̆ını tartışmak amacıyla bir araya gelmiş bir grup mühendis tarafından bu kavram ortaya atılmıştır.

Yapay zekâ kavramı her ne kadar bu dönemde ortaya atılmış olsa da yukarıda da belirtildiği gibi insan dışı varlıkların, insan davranışlarını göstermesi üzerine çalışmaları, Antik Yunan'a kadar götürmek mümkün- 
dür. Antik Yunan'da rüzgâr ile ilişkilendirilerek ve ona hükmeden bir yapay insan meydana getirme çalışması olarak Daedelus'tan bahsedilmektedir (Yılmaz, 2019, s.13). Ortaçağda yine el Cezeri'nin yapmış olduğu otomatlar görülmüştür. Bu otomatlar hidrolik yasalarla çalışmaktadır ve insanlara belirli türden içecekleri ikram edecek şekilde tasalanmıştır (Güzeldere, 1998, s.29). Günümüz yapay zekâ çalışmalarına kaynaklık edecek otomat çalışmalarının en ilkel hallerinin üretildiği bu dönemden sonra otomatlar, yerini bilgisayar destekli makinalara bırakmak durumunda kalmıştır. Teknolojinin gelişmesiyle değişen dünyada artık elektrikle ve bilgisayarla işlemler yapılmaya başlanmış ve matematiksel işlemler bilgisayarlar yardımıyla hem kısa sürede hem de daha az hatayla işlenmeye devam etmiştir.

Otomatların gelişmesi, teknolojinin gelişmesiyle doğru orantılıdır. Teknoloji ile ünlü düşünürlerin dünya görüşleri simbiyotik bir ilişki içerisindedirler. Bu iki alan da kendi arasında karşlıklı etkileşimdedir. Newton fiziği ile algılanan dünya, Galilei'nin evreni matematik olarak algılaması süreci her şeyin hesaplanabilir olduğuna kadar götürmüş ve nihayet zihinsel işlemlerin de hesaplanabilir olduğuna dair bilimsel faaliyetler gelişmiştir. Bilim insanlarının zihin ve zekâ üzerine çalışmalarının en önemli dönüm noktası Alan Turing'in yazmış olduğu "Hesaplama Makineler ve Zekâ" adlı makalesidir. Turing bu makalede bir test geliştirmiştir, bu testi geçen bir makinenin de zeki olacağını ileri sürmüştür. Bu testi geçmek için makinenin, hesaplama yapabileceğini iddia etmiştir (Haton ve Haton, 1989, s.25). Zamanla gelişen çalışmalar ve hesaplama sistemi, insan beyni ve bilgisayar arasında bir benzerlik kurarak, yapay zekâ çalışmalarının beyin endeksli yürütülmesine neden olmuştur (Brzezińska, 2019, s.10).

Yapay zekânın geçmişini kısaca anlattıktan sonra onun gelecekte nasıl bir konumda olacağı ve bu alana karşı çıkacak olan çağdaş Luditlerin neden karşı çıkacaklarını ve geleneksel Luditlerden farklarının ne olacağını tartışmak doğru olacaktır. Bu tartışmanın bilgisayar üzerine olacağı da bellidir. Çünkü aklın bilimi olarak yapay zekâ, bilgiyi işleme alan bir mekanizma gibi çalışmaktadır. Bu durumda akıl, beyin olarak ele alınd1ğında, beyin et ve kandan meydana gelmiş bir organ iken bilgisayar da akıllı program olarak anlaşılmaktadır. 
21. yüzyılda bilgi transferi, oldukça yoğun bir şekilde gerçekleşmektedir. Bilgisayarlar, teknolojik ve teknik ilerlemeler ile dünyanın hemen her alanına hükmeder hale gelmiştir. Bilim ve teknolojiyi elinde bulunduran liderler kendilerinden daha az gelişmiş ülkelere ve toplumlara bu teknolojiyi pazarlama gayreti içerisindedirler. Bilgiyi hızlı bir şekilde üreten, üretileni transfer eden bilgisayarın icadı hem yapay zekâ anlamında bir dönüm noktası olmuştur hem de bu yüzden toplumun değişmesine ön ayak olmuştur.

Yapay zekâ gelecekte insan eylemlerinin hemen hepsini yerine getirecek ve hatta daha üsttün şekilde olacağına dair bir anlayış gelişmektedir. Ancak henüz emekleme döneminde olduğu için güçlü yapay zekânın yakın zamanda oluşması mümkün görünmemektedir. Searle yapay zekâyı iki şekilde ele alır. Birincisi zayıf yapay zekâdır. Bu tür yapay zekâ, insanların bedensel etkinliklerini yerine getiren, fabrikalarda işçilerin yaptıkları bedensel işleri yapabilecek yapay zekâlardır (Searle, 1996, s.26). İkincisi güçlü yapay zekâdır. Güçlü yapay zekâ, insanın üst bilişsel süreçlerini yerine getirebilen anlama, yorumlama ve değer verme gibi etkinlikleri yapabilen düşünsel faaliyet gerçekleştiren yapay zekâdır (Searle, 2004, s.67-68).

Yapay zekânın gelecekte nasıl bir konumda olacağına dair önemli adımlardan birisi kendi tarihinden yola çıarak hangi alanda ilerleyeceğine dair rotasına bağlı gibi görünmektedir. Çünkü sadece mühendislik alanında ilerleyecek bir yapay zekâ ekonomik, askeri anlamda bir teknolojik alet olmanın dışına çıkamayacaktır ancak felsefi anlamda da insan davranışlarını yerine getirecek üst bilişsel davranışları yerine getirecek bir takım felsefi, sosyal konularla ilişkili bir alan olarak ilerleyecekse bu aşamada durum son derece önemli bir hal alacak gibi görünmektedir.

Henüz insan müdahalesine ihtiyaç duyan yapay zekâlar insanların s1nırlı düzeydeki etkinliklerini yerine getirmektedir (Çelebi ve Gütekin, 2020, s.45). Yapay zekânın şu an emekleme döneminde olduğunu ve makinalar hakketmedikleri halde şu an zeki olarak adlandırdığımızı söyleyen Hans Moravec, ilerleyen zamanlarda bilgisayarlar oldukça gelişecek ve insanlar gibi karmaşı hale gelecekler ve insanların tahmin edemeyeceği seviyelerde hareket edecektir. Ona göre bu aşamada insanlar, kendilerini ataları olarak gördükleri yapay zekâlarla gurur duyacaktır (Güzeldere, 1998, s.41). Günümüz teknoloji liderleri aynı zamanda dünyaya hükmeden liderler olarak anlaşılmaktadır. Modern dünyada Bacon’ın “bilgi 
güçtür"vecizesi ile dile gitirdiği gibi bilgiye sahip olan güce sahip olmaktadır. Bu durumda bilgiye sahip olan dünyaya sahip olacaktır.

Teknolojinin insan hayatına dolaylı etkisinden doğrudan etkisine geçiş olarak görülen yapay zekâ, insan hayatını şekillendirmekten başka insan hayatını komple değiştirecek gibi görünmektedir. Öncelikle sağlık alanında yapılan hemen her yapay zekâ çalışması, insan hayatını etkileyerek hem ömrünü uzatıyor gibi görünmekte hem de ekonomik bir kaynak olarak ele alınmaktadır. İnsanın sağlıklı yaşam ömrünü uzatan yapay zekâ sistemleri, insan ömrünü anlamlı kılan "ölüm" kavramının yok olmasına neden olacak gibi görünmektedir.

Özellikle monist yapılı dinler karakteri itibariyle birbirine benzemektedirler. Bu benzerlik çoğu zaman türler arasında bir aynılaştırma fikrinin ortaya çıkmasına neden olmaktadır (Çelebi, 2010, s.50). Örneğin insanın ölümsüzlüğü fikri, insanların birbiriyle aynılaşmış dinlere bakış açılarını da değiştirmektedir. "Yapay zekâ dini" olarak ortaya atılan bir kavramlaştırmayla yapay zekâ, kendi tanrısını ortaya koyarak, insanlığın elindeki kadim inanma duygusunu da ortadan kaldıracak gibi görünmektedir (Harris, 2017). Tanrısı "yapay zekâ" olan bir "din" meydana getirilmiş ve bu durumda insanlığın anlam arayışındaki en önemli noktalardan birisi olan din olgusu yeniden anlamlandırılmaya muhtaç hale gelmiştir.

İnsanları, dini ve sosyal tüm boyutlarıyla ilgilendiren yapay zekâ, teknoloji karşıtlığıyla bilinen Luditlerin de ilgi odağındadır. Luditler'in ve neo luditlerin teknoloji karşıtlığı belirli bir sosyal ve toplumsal alt yapının tezahürü olarak görülmektedir. Çünkü bir dönem teknoloji, işçilerin işlerini elinden alan makine üretimi, daha sonra tanrısal ve dini bir boyut alarak gelişmiştir. Zamanla kiliseye karşı koymak ve kilise tahakkümü altından kurtulmak için dine karşı teknoloji gelişimi meydana gelmiştir (Kafalı, 2019, s.154). Bu gelişimin ön hazırlayıcılarından birisi Auguste Comte olarak görülmektedir. Çünkü o yeni bir insanlık dini olarak pozitivizm dinini önermekteydi. Comte'a göre pozitif dinin en önemli ibadeti, tanriya değil topluma tapmaktır (Kalelioğlu, 2019, s.540). Yapay zekâ ile değişen teknolojinin üretim amacı, dine ve dindarlara karşı değildir, aksine bunların tamamının üstünde "insanlığa karşı bir teknoloji" gelişimi gösterilmiştir (Gencer, 2012, s.23). 
Yeni nesil luditler, yapay zekânın ilerlemesi karşısında endişelenmektedirler. Onlara göre yapay zekâ, insanlık adına önemli bir unsur olarak görülmektedir. Çünkü ilerleyen teknoloji, insanı diğer tüm varlıklardan ayıran en önemli unsur olan düşünme yeteneğinin yapay zekâlarda gelişeceğini göstermektedir. Stephan Hawking'e göre yapay zekâ, kendisini geliştirme sürecini devam ettirirse ve bu süreçte kendisini biçimlendirebilirse ondan çok daha yavaş ilerleyen ve biyolojik olarak evrilen insanlar, bu yapay zekâ ile baş edebilir gibi görünmemektedir. Günümüzde en gözde teknoloji şirketlerinin sahiplerinden olan Elon Musk, eğer önüne geçilmez ve belirli bir kural çerçevesinden üretilmesine karar verilmezse, Hawking'in iddia ettiği gibi yapay zekânın, insanlığın sonunu getireceğini düşünmektedir (Cellan-Jones, 2014). Francis Fukuyama, yapay zekâ ile güçlenmiş insanın transhümanist bağlamda ele alındığında insan türünün karşılaştığ1 en büyük tehlike olduğunu iddia etmektedir. Fukuyama'ya göre insanüstü varlık, insanın yegâne özüne zarar vermektedir (Karauğuz, 2020, s.54). Yine Fukuyama (2002, s.65) gelişen teknoloji ve yapay zekânın kullanılmasıyla ortaya çıkan yeni insan varlığında "kendisini tehdit altında bulacak olan şey insanın doğası" olduğunu belirtmiştir.

Yapay zekânın insanlar gibi hareket edip tüm güvenliği kendisine b1rakılacak bir durumda olduğunu düşünen Güney Kore, Kuzey Kore sınırına koyduğu yapay zekâlı robotlar tarafından korunmaktadır. Yanına belirli bir mesafede yaklaşanlara elini kaldır ve kimsin gibi belirli türden güvenlik sorularını yönetmektedir. Eğer karşıdan gelen kişinin sınır güvenliğini tehdit edeceğine inanırsa, vurma ile programlandığı bilinmektedir. $\mathrm{Bu}$ robotun ilerleyen zamanlarda kendi askerine ateş etmeyeceğinin herhangi bir garantisi bulunmamaktadır. Yapay zekânın insanlığa vereceği zararı göstermek için bir örnekte sosyal medyada bulunmaktadır. Microsoft, sosyal medyada TAY adında yapay zekâ ile hazırlanmış bir hesap kurmuştur. Bu hesap, kendisine sorulan sorulara cevap verecek ve kendi sorduğu sorulara karşıdan cevaplar alacaktır. İlerleyen süreçte TAY adlı hesap, çevresindeki diğer kullanıcılarla yaptığı konuşmaların sonucunda Hitler hayranı, soykırım meraklısı ve seks işçiliğini öven bir duruma gelmiştir. Daha sonra Microsoft şirketi TAY adlı sosyal hesabı kapatmak zorunda kalmıştır. DeepMind adlı elma toplamak üzere programlanmış bir bilgisayar, insan beyni örnek alınarak kurgulanmıştır. Bu bilgisayar, el- 
maları azaldığı için diğer bilgisayarların sistemini kapatarak elma toplamaya devam etmiştir. Bununla birlikte Luna adlı bir yapay zekâ programı, daha önce programlanmadığı halde sorulan tuhaf sorulara mantıklı cevaplar vermeyi başarmıştır (Çolak, 2017, s.121-125).

Yapay zekânın gelecekte ulaşacağı seviyenin ne olacağına dair öngörülerin hemen hepsi yetersiz kalacak gibi görünmektedir. Bu bağlamda, bakıldığında yapılan hemen her çalışma güçlü yapay zekâya biraz daha yaklaştı̆̆ını göstermektedir. Düşünme makinesi yapma fikri olarak gelişen yapay zekâ, Ray Kurzweil tarafından oldukça ilginç bir şekilde ifade edilmiştir. Ona göre bu teknolojik gelişme, tekillik fikri ile ölümsüzlüğü ifade etmektedir. O "The Singularity Is Near: When Humans Transcend Biology" adlı eserinde insanların kanına enjekte edilen bir tür ajan ile gelecek insan türü hakkında bir öngörüde bulunmaktadır. Ona göre ajanlar, insanın kimyasını ve biyolojik dengesini izleyerek bunları koruyabilecek çalışmalar yapabilecek ve böylelikle ölümsüzlüğü ortaya çıarabilecektir. İnsan biyolojisini ve kimyasını öğrenen bilim insanları, insan gibi düşünebilen makineler yapabilecek, içgüdüleri olan ve duyguları olan varlıklar meydana getirebilecektir (Kurzweil, 2006, s.23-67). Kurzweil'e göre yapay zekâ kendi kendisine verilen herhangi bir engeli kaldırabilecek kadar güçlü bir zekâya sahip olarak değerlendirildiğinde onun kontrolü mümkün görünmemektedir (Kurzweil, 2006, s.297). Bunun yanında yapay zekâ, zeki davranış göstermenin yanında bir de kendi zekâsını geliştirebilecek yapıda olacağından istediğine dönüşebilecek bir yapıda kendisini olgunlaştırabilmektedir.

\section{Değerlendirme ve Sonuç}

Teknoloji kelime anlamıla alet yapabilme gücü olan tekneden üretilmektedir. İnsanın yaşam kalitesini, konforunu ve iş yapabilme kabiliyetini arttırmak için gelişen teknolojik çalışmalar, değiş̧en ve gelişen dünyada farklı algılara sebebiyet vermektedir. Teknoloji kültürel, sosyal, ekonomik ve siyasal birçok alana etki edecek kadar geniş çaplı değerlendirilmesi gereken bir alandır. 21. yüzyıl teknolojik gelişme ve enformatik bakımından oldukça önemli bir yüzyıl olarak görülmektedir. Çünkü özellikle bilgisayarın bulunmasından sonra çok hızlı bilgi üretimi ve transferi sağlanmaktadır. Bunun yanında özellikle internetin de bulunmasıyla dünya küresel 
bir köy haline gelmiştir. Bu durumda üretilen hemen her teknoloji tüm dünyayı etkileyecek konumda olmuştur.

Teknolojik gelişmelerin dünyada belli başlı dönüm noktaları bulunmaktadır. Bunlardan en önemlisi ise sanayi devrimi olarak bilinmektedir. Sanayi devriminden önce iş ve emek anlamında insan gücü kullanılırken bunun temel sembolü de saban olarak görülmektedir. Ancak devrimle birlikte iş ve emeğin sembolleşen yüzünü buharlı makineler almıştır. Bu anlamda insanın kol gücünün yerine makinalar geçmiş, birçok işçinin yapabileceği işi, bazı makinalar hem kısa sürede hem de tek başına yapabilecek duruma gelmiştir. İşverenlerin maliyet açısından oldukça önemsediği makineleşme fikri hemen tüm üretim alanlarında önemli bir gelişme sağlamıştır. Bu noktadan hareketle teknolojiye karşı olumsuz bir yönelim gelişmiş ve işçiler, işlerini kaybettiklerinden dolayı bunun tek sorumlusu olarak makinaları görmüşlerdir. Makinalara karşı gelişen bu düşmanlık, bazı kesimleri keskin bir şekilde ön plana çıkmaya zorlamış ve tarihe ludizm olarak geçecek bir akımın başlamasına neden olmuştur. Geleneksel üretim araçlarına ve kendi işlerine geri dönmek için ortaya çıkan birtakım işçiler, ellerinden işlerini alan makinaları kırmaya ve yakmaya başlamışlardır.

Ludist akım, ismini Ned Ludd adında yaşayıp yaşamadığı tam olarak bilinmeyen fantastik bir kahraman olan işçiden almıştır. Ned Lud, Ludizmin en ilkel halini temsil etmektedir. Çünkü bu işçi 300'e yakın yün çorap örme makinesinin iğne ve çerçevesini kırarak, kullanılmaz hale gelmesine neden olmuştur. Bu tür eylemler, İngiltere'de o kadar yayılmaya başlamıştır ki nerede teknolojik aletlerden herhangi birisinin başına bir şey gelse "Ned Lud did it" "Lud yapmışırı" şeklinde bir deyim kullanılır haline gelmiştir. Bu akım, tarihe makine kırıcıları olarak geçmiştir. Akımın tek amacı, işçilerin kaybettiği itibarı, parayı ve işi geri kazanmalarını sağlamaktır. Bunu da zor ve güç kullanarak yapmaya çalışmışlardır. İngiltere'de artan makine kırıcılığı eylemlerini bastırabilmek için devlet, bu eylemleri yapanları teslim eden ve ifşa edenlere para ödülü vermeyi önermiş, eylemleri yapanlara da idam cezasına kadar ciddi yaptırımlar uygulamış ve hatta devlet tarafından onlarca kişi idam edilmiştir.

Geleneksel ludistlerin tavrı, makinalara karşı ortadan kaldırmak üzere olurken gelişen teknoloji, işçilerin yerine makinaları koymuştur. Fakat işçilere farklı bir iş alanı da açmıştır. Bu durumda geleneksel anlamda ludist 
tavır, yerini farklı bir bakış açısına bırakmıştır. Neo ludist olarak anılan bu akıma göre teknolojiden kaçmak ve onsuz bir hayat kurmak mümkün değildir. Devletler ve yatırımcılar teknolojiden bağımsız bir gelecek kuramamaktadırlar. Bu bağlamda devletlerin teknolojik aletleri denetleme mekanizmalarını, geliştirmeleri gerekmektedir. Yeni Luditler, devletlerin herhangi bir teknolojinin üretiminde ekonomik ve askeri anlamda kar elde edilmesine bakmanın yetersiz olduğunu düşünmektedirler. Bu akım, bu iki ölçütün geliştirilmesi ve genişletilmesi gerektiğini düşünmektedir. Teknolojinin üretilmesi aşamasında askeri ve ekonomik çıarın yanında sosyal ve kültürel sonuçlarının da değerlendirilmesi gerektiğine vurgu yapmaktadır.

Yeni ludist akım, teknolojinin kültürel ve sosyal anlamda sonuçlarının en az işlerini kaybeden işçiler kadar önemli sonuçlar doğurduğunu belirtmektedir. Örneğin herhangi bir teknolojik alet, insanlar arasında sosyal sınıf farkını arttırabilmekte ve bireyselleştirebilmektedir. Bilinen en önemli neo ludist Kaczynski teknolojinin söylendiği gibi insan huzur ve refahını arttırdığı bir durumda olmadığını belirtmektedir. Ona göre teknolojik bazı ürünler üretilirken insan sağlığını rahatlatacak ve ekonomik refahı, huzuru arttıracak düşüncesi vardı. Ancak üretilen teknoloji, tüm insanlık için değil belirli bir zümre için refah ve huzur getirmiştir. O teknolojinin, bazılarını, hala köle olarak kullanılmasına devam ettirdiğini belirtmektedir. Bu yüzden doğal yaşamın önemli olduğunu düşünerek, tüm sorumluluktan ve modern teknolojiden kaçarak yaşam sürmeyi denemiştir.

Teknolojik gelişmelerin amacı, bazen ekonomik ve askeridir ancak bazı durumlarda teknoloji, dini kaygılarla ilerlemektedir. Özellikle modern dönem sonrası, insanın ön planda olduğu süreçte teknoloji, insanların Tanrı ve din ile ilişkilerini daha doğru bir söylemle metafizik alemle ilişkilerini hedef almış gibi görünmektedir. Bu akım, Auguste Comte'un insanlık dini kurma fikri ile en üst aşamada teorik anlam kazanmış olsa da yapay zekâ fikri ile de bu düşünce somutlaşmış gibi görünmektedir. Bu bağlamda düşünüldüğünde Tanrısı yapay zekâ olan bir din fikri gelişmiş ve insanların biyolojik yaşamlarının, kimyasal durumlarının tespit edilmesiyle yapay insansı robotlar üretilmeye başlanmıştır.

Yapay insansı robotlar, insanlık tarihi açısından önemli dönüm noktası olarak görülmektedir. İnsanlığın ortaya çıkması ve dünyanın meydana 
gelmesi kadar yapay zekânın keşfi de önem arz etmektedir. İnsanın dünyada kurmuş olduğu hakimiyetin artık yapay zekâ tarafından ortadan kaldırılabileceği fikri, teknolojinin dini veya metafizik bir bağlamda değil "insana karşı teknoloji" bağlamında üretildiğini göstermektedir. Ölümsüz, insan gibi davranan robotlar veya yapay zekâ destekli makinalar insanın tüm yapıp ettiklerini yapabilecek duruma gelip insanlığı yok edebilecek donanıma sahip olabileceklerdir. Bu bağlamda düşünüldüğünde çağdaş Ludist akım olarak ifade ettiğimiz 21. yüzyıldaki teknolojik gelişmelerin karşıtlığının nedeni, geleneksel Ludistlerde olduğu gibi makinaların işçilerin işini elinden almasından dolayı değildir. Bu akımın teknoloji karşıtlı̆̆ının nedeni, neo ludistler gibi teknolojinin toplumsal ve kültürel sorunlara neden olmasından dolayı da değildir. Bu akımın teknoloji karşıtlığı, yapay zekâ ile gelişen teknolojinin insanlığın kendisini tehdit etmesinden ileri gelmektedir. Bu düşünceye göre yapay zekâ hem insanlığ hem de insan neslini tehdit etmektedir. İnsanın biyolojik yapısına benzetim kurarak oluşturulan ve düşünme yetisi, duyguları olan bir yapay zekâ, insan gibi davranarak biyolojik farklılığı ortadan kaldıracaktır. Böylece insan denen varlığ tektipleştirecek, tekilleştirecektir. Bunun yanında insanı, diğer canlılardan ayıran en önemli farkını ortadan kaldırarak düşünme eylemini insan dışında bir varlığa verilmesine neden olacaktır. Bu durum insanlığın kavramsal düzeyde değişimine neden olacaktır. Tüm bunlar göz önüne alındığında çağdaş Ludist akım, insanlığı yok ettiğinde/edeceğinden dolayı teknolojiye karşı duracak gibi görünmektedir.

Yapay zekâ karşıtı olan hemen bütün düşünürler, yapay zekânın geleceğini kestiremediği için bu alana nasıl bir perspektifle bakacağını bilememektedir. Ancak genel olarak şu bir gerçektir ki, yapay zekâ çalışmaları sonucunda üretilen yapay zekâlı robotlar gelecekte insan benzeri eylemlerin hepsini yapabilecek bir donanımda olacaktır. Zekâ, kendisine engel olunamayacak bir şey olduğundan yapay zekânın da gelişerek insan neslini tehdit edecek bir konumda olabileceği ihtimal dahilindedir. Bu bağlamda bakıldığında yapay zekâ karşıtı olan düşünürlerin insan nesli ve insanlık adına endişeleri yersiz görünmemektedir. 


\section{EXTENDED ABSTRACT}

\section{Who Will be the Ludits of Artificial Intelligence? \\ *

\author{
Abdurrazak Gültekin \\ Bingöl University
}

In our article, in which we will establish a relationship between the Ludites, known as machine-breakers in history, and the opponents of artificial intelligence, the definition of artificial intelligence, its brief history and its importance for humans will be mentioned. Machine crushers, which we will consider in the historical context, will be evaluated in the context of technology opposition from the past to the present. It is known that the movement, which was called luddism, which was anti-technology in the past, firstly opposed it on the ground that machines in general would take away people's jobs. In addition to this, secondly, the section known as technology opponents has differences in meaning from the first period ludists. Because in this period, the opponents of technology took a stance against technology, not because they took their jobs as in the first period, but on the grounds that it caused moral corruption and caused social disintegration. However, opponents of technology, which we can describe as anti-technology in the third period, and in particular, as opponents of artificial intelligence, think that technology, in particular, artificial intelligence disrupts neither people's work nor the social order. According to them, technology, in particular artificial intelligence, will destroy humanity. In this context, a descriptive narrative will be presented about why the opinions opposing artificial intelligence are opposed and at what stage this artificial intelligence will be in a position to harm people. It is clear that there are two types of artificial intelligence in this sense. Artificial intelligence, as an element that facilitates many of our works in our daily lives and is currently spreading to our every moment, is referred to as computer-assisted, simple-level machines that operate with certain commands and are not authorized to do anything other than what is given to them. This type of artificial intelligence is called weak artificial intelligence. Because such artificial intelligences have a known structure that is open to some kind of human intervention and cannot function without it. 
Apart from this weak artificial intelligence, there is also a strong artificial intelligence. Strong artificial intelligence is in a structure that can imitate people's metacognitive processes and even have self-consciousness beyond imitation. In this sense, this type of artificial intelligence is called strong artificial intelligence because it is able to perform mental processes that are unique to humans such as interpretation, understanding and comprehension. In this case, it will be stated in our article that when weak artificial intelligences fulfill human mental processes like strong artificial intelligences, their effectiveness will increase. While the weak artificial intelligence is open to human intervention, it will be able to act on its own as a strong artificial intelligence and be able to realize this action. In our article, a historical perspective on how weak artificial intelligence goes through as strong artificial intelligence will be presented. In addition, it will be emphasized that the opponents of modern technology, especially the opponents of artificial intelligence, should be referred to as strong antiAI, rather than weak artificial intelligence. Because strong artificial intelligence does not need human interventions, it can act like a human being conscious of its actions and close itself to outside interventions. Therefore, an artificial intelligence that can code its actions in a way that can destroy people may create some irreparable problems for humans. Therefore, opponents of artificial intelligence emphasize that strong artificial intelligence should be developed at a level that can harm human life as little as possible. In addition, in our article, it will be discussed whether people who oppose artificial intelligence have a similar idea with machine breakers in history. Opponents of technology, known as machine breakers, have actively aimed to destroy the heads of the machines by breaking them. At this point, in practice, an act of opposition is understood as a direct intervention. Whereas, the second period ludists focused on technology oppositions and how to use them in a culturally correct and more appropriate way instead of eliminating the technological product. In this case, it is seen that technological tools are not directly interfered with. It is seen that the opponents of the last period of technology are like the opponents of the second period, but differ in terms of discourse. Again in this study, the opposition of technology, the idea of machine breaking and the thoughts that evaluate this idea negatively will be compared. The thoughts of op- 
ponents of artificial intelligence and the similarities and differences between traditional ludists and neo-ludists will be discussed. The concerns of the opponents of 21st century technology, which we define as contemporary ludists, and in particular the opponents of artificial intelligence, are about the human generation and humanity. According to them, artificial intelligence will destroy and destroy these areas. In our study, this subject will be explained in detail.

\section{Kaynakça / References}

Aktaş, F., Çeçen , C. ve Erdemli, Y. E. (2014). Biyomedikal uygulamaları için nesnelerin interneti tabanlı veri toplama ve analiz sistemi. In B. v. Derneği (Ed.), Tip Teknolojileri Ulusal Kongresi (s.299-302). Nevşehir: Biyomedikal ve Klinik Mühendisliği Derneği.

Alkayış, Ahmet. (2021)Eğitim Felsefesi Perspektifinden Dijitalleşme ve Eğitim 4.0. Bingöl Üniversitesi Sosyal Bilimler Enstitüsü Dergisi, 21, 221-238.

Aral, V. (2014). Hukuk nedir. Hukuk Felsefesi ve Sosyoloji Arşivi, 26, 19-31.

Arif, M. (2015, 09 10). Ludizm ve teknoloji düşmanlığı. Retrieved from 09.19.2020. www.tufeyli.com: http://www.tufeyli.com/ludizm-ve-teknolojidusmanligi/.

Baransel, E. (2018). Yapay zeka olgusu gerçekleşti mi? Cyber Spot, 13, 3-5.

BBC. $(2017,1027)$. Dünya'nın ilk robot vatandaşı Suudi Arabistanlı. Retrieved from 03.08.2021, www.bbc.com: https://www.bbc.com/turkce/haberlerdunya-41780346.

Beer, M. (1989). The general history of socialism and social struggles. New York: Russell \& Russell.

Bilge, N. (2007). Hukuk başlangıcı. Ankara: Turhan Kitabevi.

Brzezińska, A. N., Introduction to Artificial Intelligence. http://zsi.tech.us.edu.pl/ nowak/bien/index.html/ Erişim Tarihi: (2019,11 24).

Bülbül, Y. ve Özbay, R. D. (2007). Osmanlı İmparatorluğu'nda teknolojiye karşı direncin iktisat tarihi. İ̧s-Gü̧̧ Endüstri İlişkileri ve İnsan Kaynakları Dergisi, 9(4), 19-41.

Can, S. ve Kılıç, S. (2019). Nöroteolojik açıdan kesb nazariyesi (Benjamin Libet Deneyi Çerçevesinde). Kader, 17(2), 380-397.

Cellan-Jones, R. (2014, 12 2). Hawking: Yapay zeka insanlığın sonunu getirebilir. Retrieved from 25.09 .2020 , www.bbc.com: https://www.bbc.com/turkce/haberler/2014/12/141202_hawking_ypay_zeka 
Cevizci, A. (2017). Büyük felsefe sözlü̆̆̈̈. İstanbul: Say Yayınları.

Chopra, S. ve White, L. (2004). Artificial agents - personhood in law and philosophy. Proceedings of the 16th European Conference on Artificial Intelligence, (p.635-639).

Çalış, Ş. ve Erkan, H. (2013). Yeni teknolojiler ve çalışma hayatı. (V. C. Özgüler, Ed.) Eskişehir: Anadolu Üniversitesi Yayınları.

Çelebi, E. ve Gütekin, A. (2020). Ontolojik sınırların belirsizliği: Yapay Zekâ, Mit ve Her (Aşk) Filmi üzerinden bir değerlendirme. İnönü Üniversitesi Kültür ve Sanat Dergisi, 6(1), 40-46.

Çelebi, E. (2010). J. P. Sartre'da özgürlügüün ontolojik temelleri üzerine. Necmettin Erbakan Üniversitesi İlahiyat Fakültesi Dergisi, 30(30), 93-104.

Çelebi, E. (2010). Kozmolojik birlik ve ontolojik çeşitlenme: İbn Arabi ve Spinoza örneği. EKEV Akademi Dergisi, 14(44), 49-60.

Çolak, E. $(2017,09)$. Yapay zeka dost mu düşman mı? Derin Ekonomi, 28, 120127.

Değirmenci, N. (2019). Teknoloji üzerine diyaloglar - 7 yapay zeka. Retrieved from 03.07.2021, edam.org.tr: https://edam.org.tr/teknoloji-uzerine-diyaloglar-7-yapay-zekal.

Doğan, K. (2019). Sürücüsüz araçlar, robotik cerrahi, endüstriyel robotlar ve cezai sorumluluk. D.E.Ü. Hukuk Fakultesi Dergisi, 21, 3219-3251.

Dönmez, S. (2020). Felsefi bağlamda yapay zeka ve 2025 sendromu. Çukurova Üniversitesi Illahiyat Fakultesi Dergisi, 20(2), 748-760.

Ergün, Ö. (2017). Kişi kavramı ve çeşitleri. Dicle Üniversitesi Adalet Meslek Yüksekokulu Dicle Adalet Dergisi, 1(1), 1-14.

Ersoy, Ç. (2018). Robotlar, yapay zeka ve hukuk. İstanbul: Onikilevha.

Eyuboğlu, İ. Z. (2017). Türk dilinin etimolojik sözlüğü. İstanbul: Say Yayınları.

Firat, M. (2020). Öğrenci destek servislerinde doğal dil işleme: GPT-3 örneği. International Conference of Strategic Research in Social Science and Education, (p.532-536).

Fukuyama, F. (2002). Our posthuman future consequences of the biotechnology revolution. New York: Picador Reading Group.

Gencer, B. (2012). Medeniyet savaşında teknoloji. Birey ve Toplum, 2(4), 7-26.

Güzeldere, G. (1998). Yapay zeka'nın dünü, bugünü, yarını. Cogito, 13, 27-42.

Hallevy, G. (2015). Liability for crimes involving artificial intelligence systems. Berkeley: Springer.

Harari, Y. N. (2018). 21. yüzyıl için 21 ders. (S. Siral, Trans.) İstanbul: Kolektif Kitap. 
Harris, M. (2017, 11 15). Inside the first church of artificial intelligence. Retrieved from 21. 09. 2020, www.wired.com: https://www.wired.com/story/anthony-levandowski-artificial-intelligencereligion/.

Haton, J. P. ve Haton, M. C. (1989). Yapay zeka (Çev.: Ayşen Ekmekçi - Alev Türker). İstanbul: İletişim Yayınları.

Hebb, D. (1949). The organization of behavior. New York: Wiley.

Hobbes, T. (1993). Leviathan. (S. Lim, Trans.) İstanbul: Yapı Kredi Yayınları.

Kaczynski, T. J. (1996). Sanayi toplumu ve geleceği. İstanbul: Kaos Yayınları.

Kafalı, H. (2019). Yapay zeka, toplu ve dinin geleceği. Ondokuz Mayıs Üniversitesi İlahiyat Fakultesi Dergisi, 46, 145-172.

Kalelioğlu, U. B. (2019). Auguste Comte'un insalık dini kurgulamasında üç hal kanunu'nun rolü ve pozitif dinin nitelikleri. Stratejik ve Sosyal Araştırmalar Dergisi, 3(3), 535-544.

Karauğuz, A. M. (2020, 05). Cennetten Kovulan insanın cenneti yeniden inşa uğraşı. Türk Dili, 821, 52-59.

Kılışarslan, S. K. (2019). Yapay zekanın hukuki statüsü ve hukuki kişiliği üzerine tartışmalar . Yıldırım Beyazıt Hukuk Dergisi, 2, 363-389.

Kurzweil, R. (2006). The singularity is near: When humans transcend biology. New York: Viking.

Locke, J. (1954). Essay on the law of nature . (W. V. Leyden, Ed.). Oxford: Clarendon Press.

Luddism . (2020, 09). Retrieved from 19. 09.2020, www.encyclopedia.com: https://www.encyclopedia.com/history/encyclopedias-almanacs-transcriptsand-maps/luddism.

Magazine, G. T. (2018). Alan Watkins'ten yapay zeka ve robotların geleceğine dair önemli öngörüler. Retrieved from 03.09.2021, www.globaltechmagazine.com:https://www.globaltechmag zine.com/2018/04/18/alan-watkinsten-yapay-zeka-ve-robotlarin-gelecegi-icin-onemli-ongoruler/.

Mcculloch, W. S. ve Pitts, W. (1943). A logical calculus of the ideas immanent in nervous activity. The Bulletin Of Mathematical Biophysics, 5, 115-133.

Nabiyev, V. V. (2016). Yapay zeka. İstanbul: Seçkin.

Newel, A. ve Simon, H. A. (1963). GPS, A Program that simulates human thought . Computers and Thought, http://digitalcollections.library.cmu.edu/awweb/awarchive? type=file Eitem $=33607$ Erişim Tarihi: 09.10.2020. 
Orhan, S. ve Savuk, F. (2014). Emek-teknoloji-işsizlik ilişkisi. Çalışma Dünyası Dergisi, 2(2), 9-24.

Searle, J. (1996). Akıllar, beyinler ve bilim. (K. Bek, Trans.) İstanbul: Say Yayınlar1.

Searle, J. (2004). Zihnin yeniden keşfi. (M. Macit, Trans.) İstanbul: Litera Yayıncilik.

Taşdemir, Ö., Özbay, Ü. V. ve Kireçtepe, B. O. (2020). Robotların hukuki ve cezai sorumluluğu üzerine bir deneme. Ankara Üniversitesi Hukuk Fakültesi Dergisi, 69(2), 793-833.

Taymaz, E. (1998). Türkiye imalat sanayiinde teknolojik değişme ve istihdam. İçinde T. Bulutay, Teknoloji ve İstihdam (s.1-38). Ankara: Orta Doğu Teknik Üniversitesi.

Thomson, E. P. (1991). The making of the english working class. New York: Penguin Books.

Toffler, A. (1996). Üçüncü dalga. (A. Seden, Trans.) İstanbul: Altın Kitaplar Yayınevi.

Umur, Z. (1983). Roma Hukuku Lügatı. İstanbul: İstanbul Üniversitesi Hukuk Fakültesi Yayınları.

Uzun, F. B. (2016). Gerçek kişilerin hak ehliyeti ve hak ehliyetine uygulanacak hukukun tespiti. Hacettepe Hukuk Fakuiltesi Dergisi, 6(2), 11-47.

Yılmaz, A. (2019). Yapay Zeka. İstanbul: Kodlab Yayın Dağıtım.

Zimmerman, E. J. (2015). Machine minds: Frontiers in legal personhood. Erişim Linki: https://www.semanticscholar.org/paper/MachineMinds\%3A-Frontiers-in-Legal-Personhood-Zimmerman/01887157279da5a53de6ab1f7442d92759b41b44. Erişim tarihi: 08.11.2021.

Zipp, J. W. (2016). The road will never be the same: A reexamination of tort liability for autonomous vehicles. Transportation Law Journal, 43, 137147.

\section{Kaynakça Bilgisi / Citation Information}

Gültekin, A. (2021). Yapay zekânın luditleri kimler olacak?. OPUS-Uluslararası Toplum Araştırmaları Dergisi, 18(44), 8432-8454. DOI: 10.26466/opus. 944914. 